\title{
Geopolítica e diplomacia monetária: o sistema dólar de tributação global e as iniciativas de desdolarização da economia internacional *
}

\author{
Mauricio Metri ${ }^{* *}$
}

\begin{abstract}
Resumo
No contexto atual de acirramento das rivalidades entre as grandes potências, o sistema monetário internacional, baseado no dólar e globalizado no pós-Guerra Fria, tem sido alvo de questionamentos e enfrentamentos. O objetivo deste artigo é analisar: as origens e o modo de funcionamento desse sistema; o poder monetário e financeiro dos Estados Unidos, expresso pela sua desproporcional capacidade de endividamento e de gasto; e as recentes reações de outros países para desdolarização da economia internacional. Como resultado, observa-se que: os Estados Unidos construíram de fato um sistema de tributação global baseado no dólar; e algumas das iniciativas recentes de desdolarização, ao incidir sobre os pilares do poder monetário dos Estados Unidos, possuem efetivo potencial perturbador da hierarquia monetária internacional.
\end{abstract}

Palavras-chave: Geopolítica, Diplomacia monetária, Estados Unidos, Dólar e Renminbi.

\section{Abstract \\ Geopolitics and monetary diplomacy: the global dollar system of taxation and the international economy's de- dollarization initiatives}

In the international context of intensifying rivalries among great powers, the international monetary system, based on the dollar and globalized in the post-Cold War era, has been questioned and tackled. The aim of this paper is to analyze: the origins and how this system works; the US monetary and financial power, expressed by the US's huge funding and spending capacity; and the most recent reactions from other countries in order to de-dollarize the international economy. It is concluded that the United States has built a system of global taxation based on the dollar; in addition, some recent initiatives of de-dollarization have attacked the bases of US monetary diplomacy since the Second World War.

Keywords: Geopolitic, Monetary Diplomacy, United States, Dollar and Renminbi.

JEL F50, E42, N40.

\section{Introdução}

Atualmente há certo consenso sobre o crescimento das rivalidades militares, políticas e econômicas entre as grandes potências, Estados Unidos, Rússia e China. Por conseguinte, expandem-se também as necessidades de gasto e de financiamento dos envolvidos direta ou indiretamente nessa nova geopolítica do século XXI. Não por outra razão, nos últimos anos, generalizaram-se os questionamentos sobre o sistema monetário internacional, estruturado com

${ }^{*}$ Artigo recebido em 26 de março de 2019 e aprovado em 3 de outubro de 2019. Uma primeira versão deste artigo foi apresentada no $4^{\circ}$ Seminário de Relações Internacionais da ABRI (Associação Brasileira de Relações Internacionais), em setembro de 2018, Foz do Iguaçu, PR, Brasil.

${ }^{* *}$ Professor de Economia Política Internacional do Instituto de Relações Internacionais e Defesa da Universidade Federal do Rio de Janeiro (UFRJ), Rio de Janeiro, RJ, Brasil. E-mail: metri@ irid.ufrj.br. ORCID: https://orcid.org/0000-0001-6564-2731. 
base no dólar. Há uma percepção de que esse sistema cria assimetrias favoráveis aos Estados Unidos em detrimento dos demais países.

O objetivo deste artigo é analisar (i) as origens e o modo de funcionamento do sistema monetário internacional do Pós-Guerra Fria, (ii) o poder monetário e financeiro dos Estados Unidos nesse sistema e (iii) as mais recentes reações defensivas patrocinadas por alguns países a partir da desdolarização de parte importante de suas operações econômicas internacionais. A hipótese deste trabalho é a de que a economia internacional está estruturada num sistema de tributação global baseado no dólar, cujas origens remetem à expansão do poder dos Estados Unidos durante a $2^{\mathrm{a}}$. Guerra Mundial, e cujos efeitos têm sido alavancar a própria atuação e presença militar dos Estados Unidos em todo globo e, também, uma reação por parte de alguns países para a desdolarização do sistema internacional.

Para tanto, depois de breves notas teóricas sobre a moeda como parte da sabedoria estratégica de um "príncipe" em razão da guerra (virtù), descreve-se o processo de construção do atual sistema de tributação global baseado no dólar, o seu modo de funcionamento e o poder monetário e financeiro dos Estados Unidos, analisando, por fim, as recentes iniciativas empreendidas por alguns países para a desdolarização do sistema internacional.

\section{A virtù monetária: breves notas teóricas sobre poder e moeda ${ }^{1}$}

Parte dos trabalhos que tratam da relação entre poder e moeda não expõe suas hipóteses teóricas, restringindo os argumentos ao campo dos acontecimentos históricos. No entanto, tal postura fragiliza a própria narrativa pelas contradições derivadas de um tratamento teóricoconceitual flexível, cujo entendimento sobre tal relação se adequa aos contextos históricos e da conjuntura.

Para evitar isso, assume-se a ideia de que a unidade de conta constitui a noção mais elementar de qualquer moeda. Os contratos de dívida em geral e os próprios preços precisam primeiro se expressar em termos da unidade de conta, antes de serem liquidados. Ademais, toda unidade de conta, inclusive a monetária, é uma denominação arbitrária e abstrata ${ }^{2}$. Depende de um poder que a escreva e a proclame. Existe um caráter compulsório ligado à moeda de conta e é a imposição de tributos que permite a sua proclamação dentro do território do Estado, exatamente por cumprir a função de "medir" e "quantificar" as obrigações tributárias. Nesse sentido, a moeda é uma contrapartida da tributação, um instrumento arbitrado pelo Estado para realizar seus gastos e aceito por ele para liquidação de dívidas tributárias ${ }^{3}$. Como a capacidade de criar impostos baseia-se no controle dos mecanismos de violência, trata-se de um conceito de moeda que incorpora a dimensão do poder e tem referência geográfica e territorial, pois os

(1) Seção baseada em Metri $(2014,2018)$.

(2) Para maiores detalhes, ver: Knapp (1905); Innes (1913); e Keynes (1930).

(3) Para maiores detalhes, ver: Knapp (1905). 
limites espaciais de sua circulação estão ligados ao alcance dos tributos e ao espaço de violência do Estado.

Com efeito, se a moeda é derivada diretamente do poder do Estado, a sua internacionalização depende do sucesso de esse mesmo Estado em projetar-se para fora de seu território nacional de origem. Não por outra razão, a moeda de referência internacional tende a ser a da autoridade estatal mais bem-sucedida nas disputas geopolíticas globais.

As vantagens da internacionalização de uma moeda não são pequenas. Em primeiro lugar, à medida que mais Estados passam a operar com outra moeda em suas transações com o exterior, a autoridade central emissora dessa moeda expansiva alavanca sua capacidade de financiamento e de gasto, uma vez que os demais são obrigados a acumular ativos líquidos denominados na referida moeda em proporção suficiente para lidar com as suas contínuas obrigações com o exterior. O próprio grau de autonomia da política cambial dos países dependerá dos seus respectivos estoques de reservas acumuladas na moeda expansiva.

Em segundo lugar, esses saldos acumulados tendem a ser drenados aos sistemas financeiros nacionais dos países que operam com base na moeda expansiva. Assim, quanto mais agentes atuarem dentro de um território monetário específico, maior tende a ser a escala, profundidade e liquidez do sistema financeiro do país cuja moeda se impõe como a de referência internacional. Criam-se posições privilegiadas às instituições financeiras desse país. Portanto, não são as inovações de uma praça financeira que estimulam a captação de recursos e, com efeito, o maior uso de sua moeda em transações internacionais. Ao contrário, é a internacionalização da moeda que garante o influxo de recursos, alavancando, por conseguinte as oportunidades de negócios e lucros nas suas praças financeiras nacionais.

Em terceiro lugar, porque as iniciativas de desenvolvimento econômico nacional acarretam a expansão da pauta e do seu volume de importações, torna-se um imperativo a todo país, à exceção do emissor da moeda de referência, exportar produtos e serviços ou valer-se do endividamento externo como estratégia para auferir a moeda internacional e, assim, poder viabilizar as compras e os pagamentos com o exterior. Não se trata de uma questão fiscal, de escassez de recursos em uma economia, mas do desafio de se obter o instrumento de liquidação de compromissos internacionais, já que estes não podem ser pagos com moeda local. Portanto, a consolidação de um território monetário global implica a imposição do problema da "restrição externa" aos países em geral. Com efeito, por meio do controle de importantes canais de administração da liquidez internacional, o país emissor da moeda de referência pode influenciar a capacidade de importação dos demais países e, portanto, suas trajetórias de desenvolvimento, como também promover crises econômicas severas. Trata-se da imposição de sanções econômicas e, em particular, financeiras.

De tal forma, se a agenda geopolítica se impuser, a diplomacia monetária será utilizada aos propósitos da política externa, buscando restringir as oportunidades de seus inimigos estratégicos do momento e, simultaneamente, aliviar as dos aliados da ocasião. Pode-se depreender uma conexão teórica e conceitual entre geopolítica, política externa e diplomacia monetária, cujo sentido último é a ressignificação da reflexão monetária, ao recolocá-la como sabedoria estratégica dos Estados nacionais diante do problema da guerra, portanto, como parte do exercício da virtù de um "príncipe". 
Para o exercício historiográfico, não basta precisar o conceito de moeda, identificar sua relação com o poder e deduzir as vantagens de sua internacionalização. É necessário também balizar os caminhos por meio dos quais uma autoridade central logra a internacionalização de sua moeda. Nesse sentido, há as conquistas de territórios, rotas comerciais, construções de sistemas coloniais e outras formas de expansão do espaço de dominação direta, quando ocorre uma ampliação do alcance da tributação, assim como a possibilidade de (re)estruturação da vida econômica nesses espaços tomados de modo a se instituir ali necessidades de importação e financiamento na moeda do Estado expansivo. Existe também a construção de relações econômicas hierarquizadas entre diferentes autoridades centrais, provenientes de negociações de acordos desiguais de natureza comercial, financeira ou de investimento, associados em geral a contextos de guerras ou de forte assimetria de poder. Por fim, há o controle de espaços estratégicos e a precificação de produtos essenciais à segurança em geral e à acumulação acelerada de capital. Tal fato compele parte dos demais países a operar na referida moeda, pois, do contrário, estaria sem acesso a esses mercados e produtos. Trata-se de um enquadramento indireto, porque coloca um dilema aos países: ou se inserem dentro do território monetário específico ou ficam vetados os acessos a produtos e mercados estratégicos. Tal situação foi decisiva em diversas experiências históricas, como, por exemplo, o caso do grosso veneziano nos Séculos XIII e XV, o caso da libra esterlina no Século XIX e o do dólar no Século XX.

Cabe observar que a projeção bem-sucedida de uma determinada moeda significa um veto a outras iniciativas semelhantes, além da imposição e da generalização do problema da restrição externa aos demais. Com efeito, as disputas monetárias adquirem uma dinâmica semelhante à de um jogo de soma zero, onde o ganho de um significa necessariamente a perda para os outros. Por essa razão, as iniciativas de veto à projeção de uma moeda são tão importantes quanto as de promoção de uma moeda. Dependendo das circunstâncias, as estratégias focam mais os vetos às moedas de outros do que a promoção de sua própria.

\section{A diplomacia monetária estadunidense e a consolidação do privilégio exorbitante}

Ao longo da Segunda Guerra Mundial, os Estados Unidos lograram tornar sua moeda a de referência internacional. Para tanto, foram fundamentais: (i) a difusão do mecanismo do lend-lease $e^{4}$, (ii) os Acordos Internacionais negociados ainda no contexto dos $\operatorname{conflitos}^{5}$, e (iii) o controle direto sobre os principais centros de gravidade da produção mundial de petróleo ${ }^{6}$.

No imediato Pós-Guerra (1947), a estratégia de reconstrução da Europa e do Japão no contexto da política de contenção da União das Repúblicas Socialistas Soviéticas (URSS) via Plano Marshall acabou por reforçar a posição do dólar no sistema internacional ao situá-lo

(4) Instrumento de endividamento (em dólar) dos países aliados durante a guerra, definidos pelos Atos de Neutralidade dos Estados Unidos de 1941. Ver: Metri (2015).

(5) Definição da moeda de denominação das compensações impostas aos derrotados nos acordos de Yalta (fevereiro de 1945) e ratificados em Potsdam (julho de 1945), e da moeda de referência nos acordos constitutivos das novas instituições financeiras multilaterais (Fundo Monetário Internacional - FMI e Banco Internacional para a Reconstrução e o Desenvolvimento - BIRD) ligadas ao novo sistema monetário internacional (Acordos de Bretton Woods de 1944). Ver: Metri (2015).

(6) A precificação em dólares do petróleo da Arábia Saudita a partir de 1945. Ver: Metri (2015). 
Geopolítica e diplomacia monetária: o sistema dólar de tributação global e as iniciativas de desdolarização...

como parte da solução ao problema do abastecimento de petróleo e da própria ajuda econômica em geral ${ }^{7}$.

O mesmo ocorreu nas décadas seguintes por conta do prolongamento da Guerra Fria e da estratégia de contenção da URSS. A disposição estratégica dos Estados Unidos, tanto em facilitar o acesso das exportações dos países aliados ao seu mercado interno, quanto em incentivar o financiamento e o investimento direto de suas empresas e bancos no exterior, proporcionaram aos aliados as condições externas favoráveis ao desenvolvimento econômico nacional. No entanto, em contrapartida, esse "desenvolvimento a convite" reforçou a posição da moeda estadunidense, ao consolidar essas economias nacionais dentro do território monetário dólar ${ }^{8}$.

Por conseguinte, os Estados Unidos alavancaram sua capacidade de gasto e de financiamento dado que os países do mundo capitalista passaram a acumular reservas em dólares em volumes crescentes. Suas instituições financeiras, num primeiro momento, conquistaram posição privilegiada nas operações internacionais por serem as únicas com capacidade de manter depósitos e criar poder de compra em dólares ${ }^{9}$. A política externa estadunidense ganhou um importante instrumento de reforço: no contexto da Guerra Fria, ajuda econômica para os aliados mais estratégicos e sanções e bloqueios econômicos aos inimigos ${ }^{10}$.

No entanto, os compromissos de Bretton Woods impuseram algumas restrições ao exercício do privilégio exorbitante. Esses limites envolviam tanto a defesa da paridade ourodólar, quanto a busca por um equilíbrio no saldo de Transações Corrente do Balanço de Pagamentos dos Estados Unidos, de modo a se evitar um crescimento desproporcional de obrigações externas (em dólares) sem um aumento correspondente das reservas em ouro. Nesse

(7) “Aqueles que em Paris estavam conduzindo o Programa de Recuperação da Europa não se preocupavam muito com a disponibilidade física do petróleo. Eles simplesmente confiavam nas companhias para certificarem-se de que o petróleo estaria lá. Entretanto, o petróleo tinha de ser importado, e isso fez com que se tornasse uma parte não só da solução, mas também de um problema. Aproximadamente a metade do petróleo europeu era proveniente das companhias americanas, o que significava que teria de ser pago em dólares. Para a maior parte dos países europeus, o petróleo era o item que mais pesava em seus orçamentos em dólar. Estimou-se, em 1948, que mais de $20 \%$ do total do Plano Marshall, nos quatro anos subsequentes, seria destinado à importação de petróleo e de equipamentos correlatos.” (Yergin, 1991, p. 476).

(8) “A integração europeia e a expansão econômica mundial exigiam uma reciclagem muito mais abrangente da liquidez mundial [em dólares] do que estava implícita no Plano Marshall e em outros programas de assistência. Essa reciclagem mais abrangente [em dólares] acabou por se materializar no mais maciço esforço de rearmamento que o mundo já vira em tempos de paz." (Arrighi, 1994, p. 306).

(9) Num segundo momento, para preservar Londres como uma importante praça financeira internacional, o Estado inglês autorizou em 1959 o estabelecimento em seu território de um mercado interbancário paralelo e autônomo aos demais sistemas financeiros nacionais, inclusive ao seu, operando em dólares e outras moedas internacionais conversíveis. Do contrário (fora do dólar), os capitais financeiros ingleses não seriam capazes de concorrer com os norte-americanos. Para maiores detalhes, ver: Helleiner (1994, cap. 4).

(10) Esse foi o caso da China depois da Revolução de 1949, quando os Estados Unidos alteraram a Lei de Controle de Exportações baseada na Lei de Comércio com o inimigo de 1917. A Lei de 1949 proibiu a realização de negócios entre nacionais e residentes com países comunistas. "With respect to China and Cuba, the result was once a total prohibition against exportation of any goods or unpublished technical data. This prohibition applied even to goods and data which were not of U.S. Origin." (Grzybowski, 1973, p. 176). 
contexto, a gestão liquidez internacional ocorria sobretudo com base no que Charles Kindleberger denominou de aprofundamento financeiro, em que a economia dos Estados Unidos funcionava como um banco para o sistema internacional, emprestando a longo e captando a curto prazo através por meio de uma conta de capitais autônomos, sem variações nas reservas de ouro, ou seja, na conta de capitais compensatórios ${ }^{11}$.

Já nos anos 1970s, após a ruptura unilateral da paridade do dólar-ouro em 1971, a diplomacia monetária em defesa do dólar apoiou-se ainda mais sobre o petróleo. A presença militar estadunidense e seu poder de influência sobre as autoridades sauditas garantiram que a cotação do petróleo exportado pela Arábia Saudita seguisse sendo feita em dólares a despeito do seu comportamento nos mercados de câmbio e das propostas para sua substituição como moeda de cotação do petróleo exportado pela Organização dos Países Exportadores de Petróleo (OPEP). Como contrapartida ao apoio da Arábia Saudita e para arrefecer as pressões de outros países da OPEP, os Estados Unidos concordaram com um choque de preços do petróleo em 1973 a fim de recompor as perdas dos exportadores decorrentes da desvalorização do dólar, porém exigiram que a reciclagem dos petrodólares fosse realizada em Wall Street ou (também em dólares) nos euromercados, sobretudo com investimentos em U.S. Treasuries ${ }^{12}$.

Os Estados Unidos valeram-se também de seu poder de veto dentro do FMI para impedir as propostas de substituição do dólar pelos Direitos Especiais de Saque como moeda de referência internacional. Na ocasião, bloquearam da mesma forma as propostas de reciclagem dos petrodólares via $\mathrm{FMI}^{13}$.

Na década de 1980, a diplomacia monetária dos Estados Unidos esteve ligada a princípio ao choque dos juros do FED de $1979^{14}$, seguida pelas iniciativas no âmbito dos Acordos do Plaza (1985) e Louvre (1987) ${ }^{15}$. Segundo Tavares, a "diplomacia do dólar forte" visava tanto a defesa da moeda dos Estados Unidos na hierarquia monetária internacional quanto o enquadramento dos países do centro a partir da coordenação forçada ou não de políticas econômicas, orientadas a um ajuste recessivo, e de implementação de uma agenda global de liberalização e de desregulamentação financeira. Em suas palavras,

Na reunião mundial do FMI de 1979, Mr. Volcker, presidente do FEDFed, retirou-se ostensivamente, foi para os EUA e de lá declarou ao mundo que estava contra as propostas do FMI e dos demais membros (...). A partir desta reviravolta, Volcker subiu

(11) Para maiores detalhes, ver: Kindleberger (1987, 1993, p. 453), Hicks (1989) e Minsky (1993).

(12) "In May 1973, with the dramatic fall of the dollar still vivid, a group of 84 of the world's top financial and political insiders met at Saltsjöbaden, Sweden, the secluded island resort of the Swedish Wallenberg banking family. This gathering of Prince Bernhard's Bilderberg group heard an American participant, Walter Levy, outline a 'scenario' for an imminent 400 per cent increase in OPEC petroleum revenues. The purpose of the secret Saltsjöbaden meeting was not to prevent the expected oil price shock, but rather to plan how to manage the about-to-be-created flood of oil dollars, a process U.S. Secretary of State Kissinger later called 'recycling the petrodollar flows."' (Engdahl, 1992, p. 130). Ver: também, Spiro (1999); Clark (2005); e Metri (2017).

(13) Para maiores detalhes, ver: Helleiner (1994, p. 111).

(14) Para maiores detalhes, ver: Tavares (1984) e Tavares e Melin (1997).

(15) Para maiores detalhes, ver: Funabashi (1988) 
violentamente as taxas de juros interna e declarou que o dólar manteria sua situação de padrão internacional e que a hegemonia da moeda americana iria ser reestruturada (Tavares, 1985, p. 33).

Tais iniciativas da "diplomacia do dólar" estiveram associadas a outras duas: a "diplomacia das armas" 16 voltada à radicalização da estratégia de enfrentamento da URSS com base numa intensificação da corrida armamentista; e a "diplomacia do petróleo" com propósito de derrubar os preços do petróleo nos mercados internacionais na segunda metade dos 1980s, a fim de estrangular a capacidade de importação soviética ${ }^{17}$.

\section{A restauração da ordem liberal e a expansão do privilégio exorbitante}

Desde o governo Nixon (1969-1974), no contexto da diplomacia triangular e de reformulação da geo-estratégia dos Estados Unidos, da qual derivou a própria ruptura dos acordos de Bretton Woods, começou a se forjar nos Estados Unidos as primeiras propostas para restauração liberal da ordem financeira internacional. Tratou-se de um retorno às intenções do imediato pós-guerra Guerra (1945-47), abortadas pelo então presidente Harry Truman em razão da Guerra Fria.

A restauração liberal caracterizou-se sobretudo por três processos: i) a liberalização dos fluxos financeiros internacionais, isto é, a remoção em diversos países dos controles sobre os movimentos de capitais entre residentes e não-residentes; ii) a desregulamentação dos sistemas financeiros nacionais em geral, ou seja, a redução das restrições internas, de natureza legal e institucional, às atividades financeiras, padronizando e homogeneizando os mercados; iii) e a generalização das práticas de securitização nos mercados internacionais, isto é, a expansão dos financiamentos por meio da colocação direta de papéis de propriedade ou de dívida nos mercados internacionais de capitais.

Estes processos tiveram início em 1974, quando os Estados Unidos implementaram um programa de abolição dos seus controles sobre os movimentos de capitais e, simultaneamente, insistiram na definição de limites ao direito dos demais países quanto à mesma questão. No ano seguinte, promoveram a desregulamentação de seu sistema financeiro nacional. Não tardou e a Inglaterra acompanhou-os, quando, em 1979, o governo de Thatcher revogou o sistema de controle de divisas que operava há cerca de 40 anos. A desregulamentação do sistema financeiro inglês começou em 1983 e terminou em 1986.

Na década de 1980, a ordem financeira liberal espraiou-se por importantes economias do centro. Na Europa, a França lançou o programa de abolição de seus controles de capitais, ainda no governo socialista de François Mitterrand em 1984. A Alemanha Ocidental, durante o governo de Helmut Kohl, seguiu na mesma linha, acompanhada pela Dinamarca, que extinguiu

(16) Para maiores detalhes, ver: Tavares (1984).

(17) Para maiores detalhes, ver: Metri (2013) e Brandão (2016). 
seus controles em 1984, e a Holanda, em 1986. Os países da península escandinava -, Suécia, Noruega e Finlândia -, iniciaram suas reformas também em meados daquela década ${ }^{18}$.

Nos 1990s, à exceção da China e da Índia, foi a vez dos países da periferia e da antiga área de influência soviética, inserirem-se na globalização financeira, via Consenso de Washington ou via programas de Terapia de Choque sob coordenação de economistas liberais ocidentais.

Como resultado da globalização, no final do século XX, as operações financeiras nos mercados internacionais expandiram-se de forma desproporcional quando comparadas à economia real. Essa expansão dos fluxos de capitais, combinado à crescente liberalização de seus movimentos, teve como desdobramento uma pressão significativa sobre os mercados de câmbio e, com efeito, uma expressiva instabilidade nas paridades entre as principais moedas do mundo a partir de meados dos anos 1970 e, com maior vigor, nas décadas seguintes.

Nesse novo contexto, a autonomia sobre a política econômica e a promoção do desenvolvimento nacional tornaram-se mais complexas, acentuando o papel das reservas internacionais. É importante observar que, durante o regime de Bretton Woods (1947-1971), devido aos controles de capitais, as taxas de câmbio acompanhavam notadamente os saldos em transações correntes, e as taxas de juros internas podiam ser definidas em patamares diferentes daqueles praticados nos mercados internacionais. Por sua vez, na ordem liberal do pós-Guerra Fria, marcada pela ausência de controle de capitais e pelo crescimento desproporcional dos fluxos de capitais especulativos, as taxas de câmbio passaram a acompanhar sobretudo os diferenciais de juros, e a capacidade de intervenção das autoridades monetárias nacionais passou a requerer um estoque crescente de reservas internacionais em seus respectivos bancos centrais.

Conforme dito, as receitas de exportação têm uso estratégico para flexibilização das restrições à capacidade de importação. Mas, no pós-Guerra Fria, dado o crescimento e a liberdade dos fluxos de capitais, o desafio foi amplificado. Tornou-se necessário acumular, em maior escala, reservas internacionais via exportações para fazer frente à violência que os ataques especulativos adquiriram, para assim garantir a autonomia sobre a política econômica, resguardar a capacidade de importação e viabilizar o desenvolvimento econômico.

Para se ter uma ideia, a China, em 1990, tinha um estoque de US\$ 20 bilhões em reservas; em 2000, chegou a quase US\$ 160 bilhões; em 2010, algo em torno dos US\$ 2,5 trilhões; e, em 2015, alcançou o patamar de quase US\$ 4 trilhões. O Japão, por sua vez, em 1990, possuía algo próximo a US\$ 74 bilhões em reservas; em 2000, passou para mais de US\$ 340 bilhões; em 2010, ultrapassou a marca do US\$ 1 trilhão; e, em 2018, tem tinha aproximadamente US\$ 1,260 trilhões trilhão em reservas. A Coréia Coreia do Sul, em 1990, detinha um pouco mais de US\$ 15 bilhões; em 2000, passou para quase US\$ 100 bilhões; em 2010, aproximadamente US\$ 270 bilhões; e, em 2018, US\$ 400 bilhões. A Índia, em 1998, detinha US\$ 29 bilhões e, em 2018, chegou a algo próximo dos US\$ 400 bilhões. A Alemanha,

(18) Para maiores detalhes, ver: Helleiner (1994, cap. 7). 
em 2000, detinha US\$ 95 bilhões em reservas; em 2010, aproximadamente US\$ 130 bilhões; e, em 2018, US\$ 160 bilhões. A França, em 1990, possuía US\$ 50 bilhões; em 2000, algo próximo a US\$ 75 bilhões; em 2010, chegou à faixa dos US\$ 110 bilhões; e, em 2018, US\$ 150 bilhões ${ }^{19}$.

Nesse processo, infere-se o predomínio do dólar como principal moeda na composição das reservas internacionais. De acordo com os dados do FMI relativos à currency composition of official foreign exchange reserves (COFER), em 1990, das reservas alocadas, $47 \%$ eram em dólares; em 2000, 71\%; em 2010, 62\%; e, em 2017, 64\%20. Na composição das reservas em dólar nos Bancos Centrais há o predomínio dos títulos públicos dos Estados Unidos.

Segundo o Departamento do Tesouro dos Estados Unidos, em 2012, de todos os tipos de US securities mantidos por estrangeiros, $40 \%$ eram de títulos públicos; em 2014, 37\%; em 2016, 36\%; e, em 2018, 32\% ${ }^{21}$.

O Gráfico 1 a seguir mostra o crescimento da dívida pública dos Estados Unidos. Mesmo quando analisada em termos do PIB, observa-se uma significativa expansão nas últimas quatro décadas. Em 1981, ela correspondia a 31\% do PIB, ultrapassando, nos últimos anos, a marca dos $100 \%$, algo ocorrido pela última vez ainda no contexto do esforço de guerra (durante os anos de 1945-47).

Gráfico 1

A dívida pública federal dos Estados Unidos

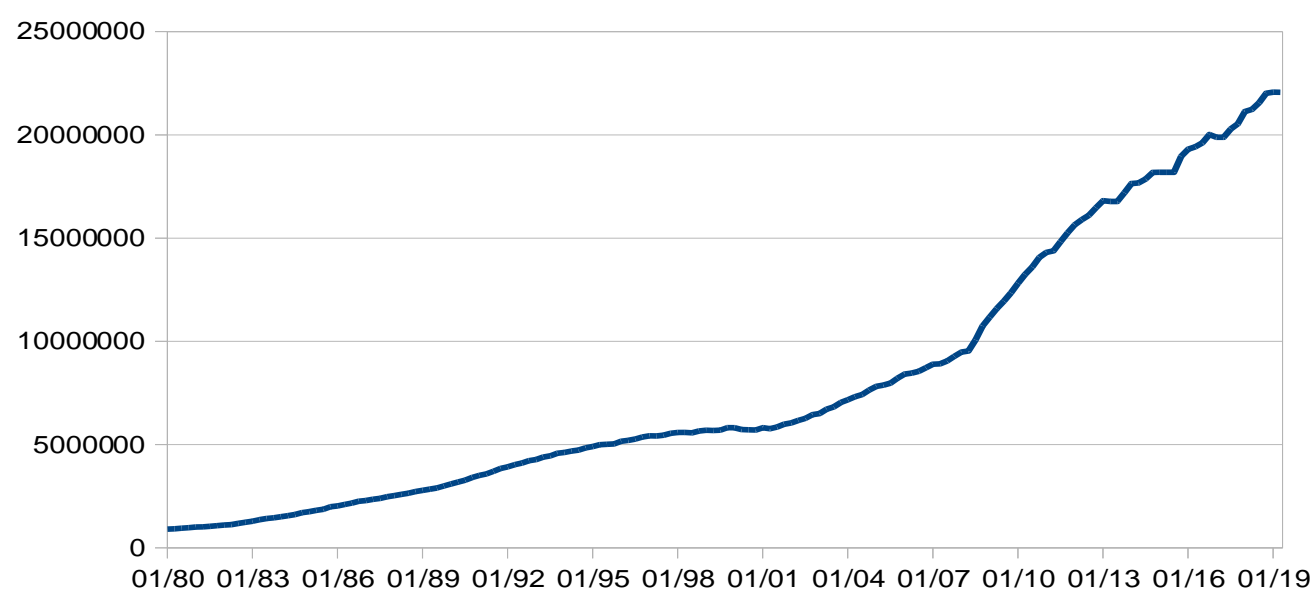

(US\$ milhões)

(19) Fonte dos dados: Trading Economics. Disponível em: https://pt.tradingeconomics.com.

(20) Fonte dos dados: Fundo Monetário Internacional. Disponível em: http://data.imf.org/.

(21) Fonte dos dados: Departamento do Tesouro dos Estados Unidos. Disponível em: https://ticdata.treasury.gov/Publish/shla2018r.pdf. 


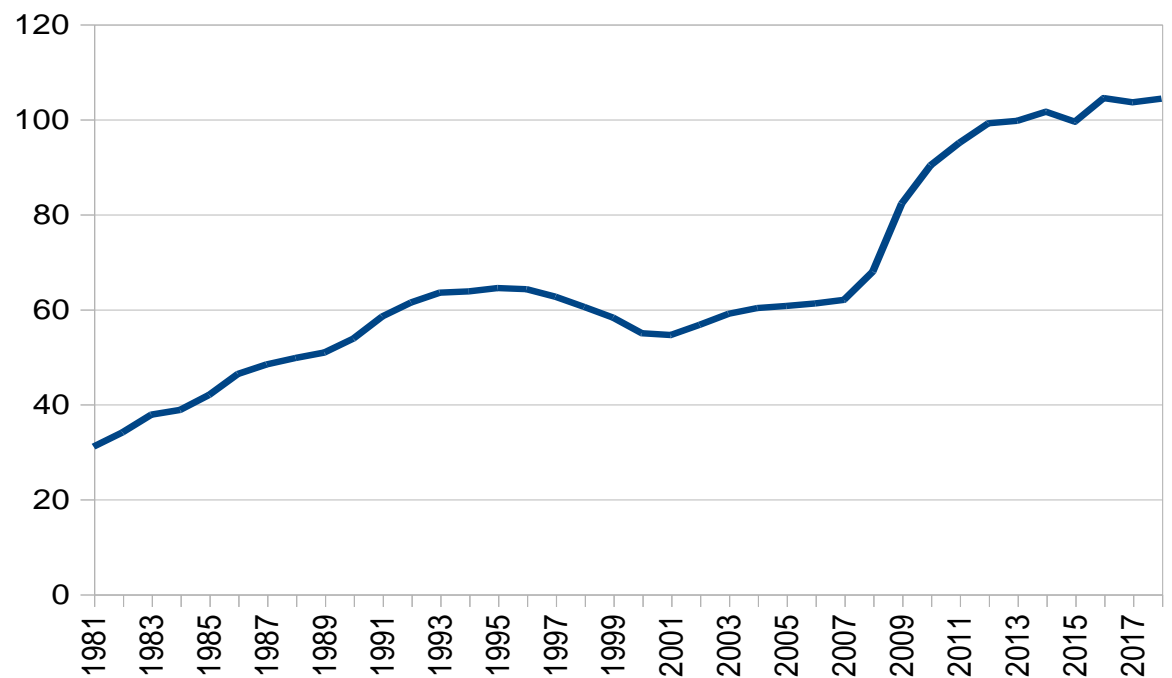

(\% do PIB)

Fonte: Federal Reserve Bank of St. Louis. Disponível em: https://fred.stlouisfed.org/series/GFDEBTN.

Retomando o argumento, ao impelir o mundo a operar em dólares com base num sistema financeiro internacional desregulado e liberalizado, pelas razões descritas anteriormente, os Estados Unidos conseguiram fazer com que os seus títulos públicos tivessem uma demanda sem limite aparente, o que proporcionou a esse ativo financeiro risco de crédito mínimo, alta liquidez e amplo espectro de maturidades, além de uma infraestrutura de mercado sofisticada. Não por outra razão, esses ativos passaram a prover a taxa de juros de referência para o processo de formação de preço dos demais títulos dos mercados privados de renda fixa. Tornaram-se importantes veículos de hedge para posições em outros títulos, pois viabilizaram a administração dos riscos decorrentes de alterações nas taxas de juros. Facilitaram o financiamento de posições no mercado financeiro e a administração da liquidez. São também um instrumento seguro para investimento de longo prazo, em razão do seu pequeno risco de crédito, importante para a composição das carteiras dos investidores institucionais. Por último, tornaram-se o mais relevante porto seguro do sistema financeiro internacional. Na verdade, sendo o principal ativo em termos de liquidez, os Treasuries funcionam como autênticas quasemoedas $^{22}$.

(22) Para maiores detalhes, ver: Metri (2003). 
Essa demanda sem limites aparentes pelos U.S. Treasuries foi percebida por Tavares ainda nos primeiros momentos da formação desse sistema globalizado.

Um aspecto muito importante é que isso [uma maciça transferência de renda e de capitais do resto do mundo para os EUA] permite fechar o déficit estrutural financeiro do setor público. Tudo se passa como se cada vez que o FED Fed joga títulos de dívida pública no mercado, ele tivesse certeza de que os títulos serão colocados em todas as estruturas bancárias e junto a todos os rentistas, de países desenvolvidos ou não (Tavares, 1984, p. 41, grifo nosso).

Pelo lado das contas externas, o sistema monetário pós-Guerra Fria vem proporcionando expressiva liberdade para os Estados Unidos acumularem crônicos e estruturais desajustes. De acordo com o Gráfico 2, os seus saldos em Transações Correntes eram ligeiramente positivos em 1980 e 1981, mas, a partir do ano seguinte, a economia estadunidense passou a apresentar sucessivos déficits, puxados pelos resultados negativos na Balança Comercial. A deterioração da Conta Corrente que se seguiu no restante dos 1990s mostrou-se ainda mais expressiva. Após 1991, o superávit foi rapidamente revertido, e a deterioração continuou por mais de 15 anos até a crise econômica de 2008, quando ocorreu um ajuste de metade do déficit, embora sem a sua eliminação, mantendo-se desde então ainda em patamares bastante elevados.

Gráfico 2

Saldo em transações correntes dos Estados Unidos (US\$ milhões)

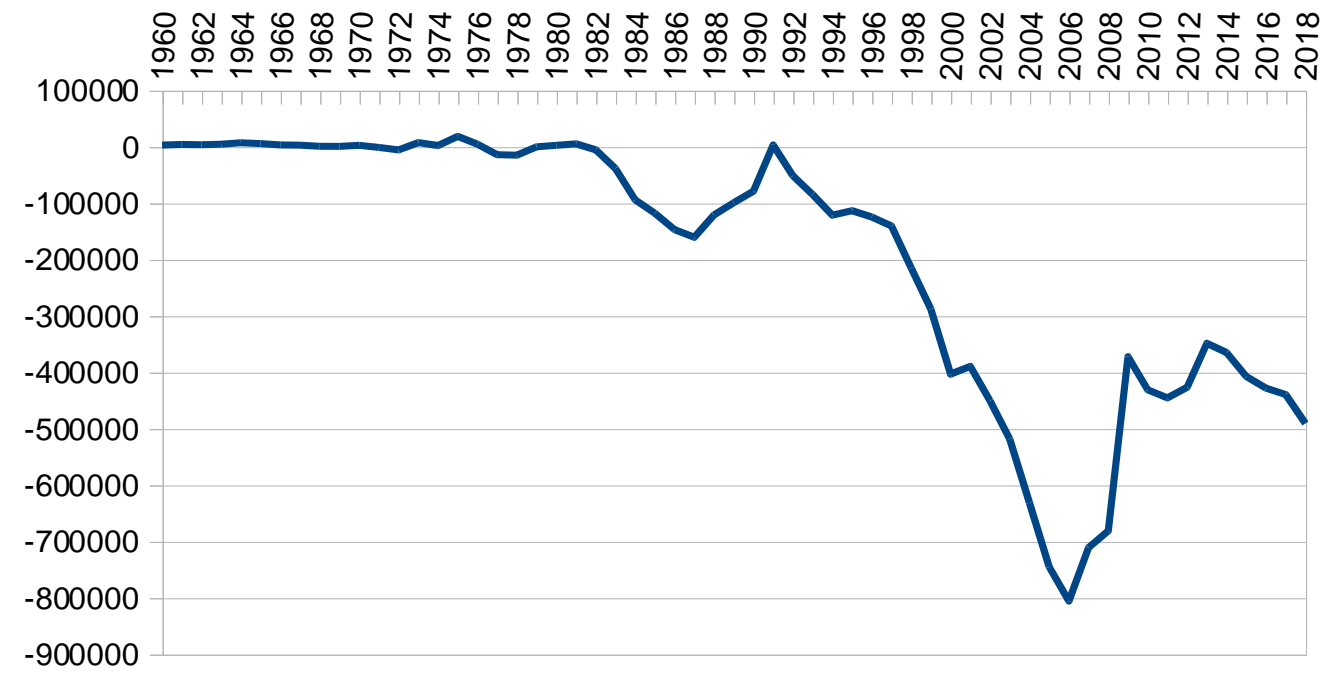

Fonte: Bureau of Economic Analysis. Disponível em: http://beagov.prod.acquia-sites.com.

Pelo lado da conta de capital, observa-se que os movimentos compensatórios foram praticamente nulos, e os investimentos em carteira foram os mais significativos dentre os fluxos 
autônomos. É nesse sentido que os déficits em Transações Correntes devem ser entendidos como a contrapartida da capacidade de a economia dos Estados Unidos absorver parte significativa da riqueza financeira mundial, sobretudo na forma de capital de curto prazo (especulativo), para dentro de seu sistema financeiro nacional.

Em resumo, a despeito dos déficits crônicos e estruturais em Transações Correntes, não há fuga das posições em dólares ou ataques especulativos. Não existem pressões para que os Estados Unidos ajustem seus desequilíbrios macroeconômicos. Este país consegue transferir o ônus de seus desajustes aos demais a partir do momento em que a melhor estratégia para o desenvolvimento e uma inserção econômica autônoma é acumular em escala crescente reservas em ativos denominados em dólar, sobretudo os U.S. Treasuries.

Portanto, a capacidade de financiamento e de gasto dos Estados Unidos no pós-Guerra Fria está ligada à montagem desse sistema monetário, que vem lhe permitindo alavancar ainda mais sua efetiva presença militar em todos os continentes, mares e oceanos. No mundo pósGuerra Fria, pode-se falar de um privilégio exorbitante ampliado. O que para os demais se apresenta como sinal de fraqueza e dependência, para os Estados Unidos, o endividamento excessivo assemelha-se mais a um sinal de força, baseado num sistema de extorsão e tributação global.

\section{A geopolítica do século XXI e as iniciativas de desdolarização}

Nas últimas décadas, tem havido uma intensificação das rivalidades entre as principais potências. As origens desse processo remontam ao fim da Guerra Fria, quando, ainda no governo de Bush (pai), os Estados Unidos refizeram sua geoestratégia e passaram a se orientar contra o aparecimento de potências regionais. Nesse sentido, ao invés de desacelerarem sua expansão militar em razão do fim de seu principal inimigo estratégico até então, a URSS, os Estados Unidos seguiram ampliando sua presença global.

Nesse contexto, os Estados Unidos aumentaram seu cerco à Rússia ao patrocinar a expansão da Organização do Tratado do Atlântico Norte (OTAN) sobre a Europa Central. Ingressaram na organização: Polônia, República Tcheca e Hungria em 1999; Bulgária, Estônia, Letônia, Lituânia, Romênia, Eslováquia e Eslovênia em 2004; e Albânia e Croácia em 2009.

Não menos importante, no pós-Guerra Fria, os Estados Unidos têm participado de ações militares sucessivas: Guerra do Golfo (1990-91); Guerra da Bósnia (1992-95); Guerra do Kosovo (1996-99); Guerra do Afeganistão (2001-hoje); Guerra do Iraque (2003-11); Guerra no Líbano (2006); Intervenção Militar na Líbia (2011); Guerra da Síria (2011-hoje); além de participações indiretas como na Guerra da Ucrânia (2014-hoje) e na Guerra do Iêmen (2015hoje).

Observa-se também, que, em 2015, os Estados Unidos possuíam uma presença militar global assentada num conjunto de 800 bases militares. Para se ter uma ideia da assimetria, enquanto os Estados Unidos possuem 800 bases espalhadas no pelo mundo, as demais grandes 
Geopolítica e diplomacia monetária: o sistema dólar de tributação global e as iniciativas de desdolarização...

potências somadas detêm apenas a $30^{23}$. A maior parte das bases estadunidenses está localizada no Rimland de que falou o geopolítico N. Spykman, cercando a Eurásia, com destaque para a China e a Rússia.

Não são propriamente os contribuintes estadunidenses que sustentam a capacidade de gasto e de financiamento relativa à projeção recente de seu Estado nacional, suas guerras e sua presença militar global, mas, sim, a emissão sem limite aparente de dívida pública e a sua absorção contínua pelos demais países e agentes privados que operam nos mercados financeiros globalizados.

Diante desse quadro, alguns países têm empreendido iniciativas de enfrentamento defensivo em diversos campos estratégicos, como, por exemplo, o militar, o tecnológico, o econômico e, também, o monetário.

No entanto, há uma certa confusão ao se interpretar as disputas monetárias características deste início de Século XXI. A maior parte dos analistas atribui grande peso aos fatores econômicos. Apontam, por exemplo, o crescimento econômico chinês e o aumento de sua participação na economia internacional como elementos determinantes para o enfraquecimento do dólar em detrimento do renmimbi. Isto porque, depois de expandir seu PIB a uma taxa média de quase $10 \%$ a.a. ao longo das últimas três décadas, a China se tornou a segunda maior economia do mundo em 2010, ultrapassando seu vizinho, o Japão.

Tal fato tem incentivado agentes econômicos de outros países a usar o renminbi em suas transações com a China. Algo que também está relacionado com a internacionalização das empresas e bancos chineses. No entanto, é preciso ponderar que o uso do renminbi na economia internacional não tem apresentado um dinamismo compatível com a expansão recente de sua economia. Em 08/2015, por exemplo, a moeda chinesa encontrava-se em quarto no ranking das moedas mais utilizadas em pagamentos globais com apenas 2,79\% das transações, pouco à frente do iene $(2,76 \%)$, e bastante atrás da libra esterlina (8,45\%), do euro $(27,20 \%)$, e do dólar $(44,82 \%)^{24}$.

Nesse contexto, o governo chinês vem procurando facilitar a difusão de sua moeda a partir de uma série de iniciativas, como, por exemplo: o programa de liquidação de operações comerciais transfronteiriço de 2009 (Cross-Border Trade Settlement), que envolve sobretudo países da Associação de Países do Sudeste Asiático (ASEAN); a criação do sistema de pagamentos internacional chinês de 2015 (the China International Payment System - CIPS), onde já há a participação de importantes bancos internacionais, ocidentais inclusive (por exemplo, Citi Bank, HSBC e Deutsche Bank); e os acordos bilaterais de swaps cambiais, sobretudo desde 2009, com dezenas de outros países ${ }^{25}$.

(23) Para maiores detalhes ver: Vine (2015, p. 4-5).

(24) Financial Times. China launch of renminbi payments system reflects Swift spying concerns. October 8, 2015.

(25) Para maiores detalhes, ver: Martins, (2017) e Cintra e Martins (2013). 
A questão é que um aumento no uso de uma moeda nacional na economia internacional, derivado de um maior dinamismo econômico de seu respectivo país (ou região) num determinado momento da história, não é um fato novo. Isto ocorreu, por exemplo, com a moeda japonesa (o iene) ao longo das décadas de setenta e oitenta, e com o euro na década de noventa e no início deste século. No entanto, tais processos não alteraram os pilares da hierarquia monetária centrada no dólar. Trata-se de um efeito natural resultante de um desenvolvimento acelerado, mas sem estofo por si só para deslocar a posição da moeda de referência internacional, cujas bases de sustentação são outras.

A mesma advertência vale para as análises que enfatizam o valor das moedas nos mercados de câmbio, definindo-o como elemento decisivo para a posição de uma moeda no sistema internacional. As variações cambiais de uma moeda não têm relevância para determinar sua ascensão na hierarquia monetária. Se assim fosse, o dólar já teria deixado de ser a moeda de referência nas últimas décadas em razão de sua oscilação excessiva em relação a outras moedas conversíveis.

O que a história tem ensinado, seja pela experiência inglesa no século XIX, estadunidense no século XX ou mesmo, a da Sereníssima República de Veneza nos séculos XIII e XV, é que o sucesso para a ascensão de uma determinada moeda como a de referência em um espaço internacional reside na capacidade de sua autoridade central (estatal) construir comunidades de pagamentos organizadas com base exclusivamente na sua moeda de conta, a partir de ações diplomáticas e militares. Não são as forças de mercado, através de processos de adesão de agentes econômicos dispersos que consagraram uma hierarquia monetária. São outras as fontes de tensões e enfrentamentos ao dólar hoje.

Pode-se falar, primeiramente, das disputas em torno da moeda de cotação (precificação) do petróleo comercializado internacionalmente. Nesse tema, os interesses de Rússia, China, Irã, Turquia, Índia e Venezuela, por razões distintas, são convergentes. Em 2012, por exemplo, Irã decidiu exportar seu petróleo em renminbi para a China ${ }^{26}$. Ainda nesse contexto, em 2018, a China lançou os primeiros contratos futuros de petróleo denominados em renminbi (petroyuan) negociados no mercado futuro de Xangai, concorrendo com as praças de Nova York e de Londres, onde tais contratos são transacionados em dólar ${ }^{27}$. A Rússia, por sua vez, tem aumentado os acordos bilaterais para negociações fora do dólar, inclusive de seu petróleo, além de se desfazer de parte significativa de suas reservas em dólar e anunciar a emissão de títulos de dívida soberanos em moeda chinesa ${ }^{28}$. Ainda no que se refere ao petróleo, há também a decisão do governo da Venezuela, em outubro de 2018, de abandonar num futuro

(26) Financial Times. Iran accepts reniminbi for crude oil. May 7, 2012.

(27) Foreign Policy. China's bid to upend the global oil Market. January 18, 2018. Ver também em: Financial Times. The week in energy: China, oil and the dollar. April 7, 2018.

(28) Bloomberg. Disponível em: https://www.bloomberg.com/news/articles/2017-11-30/russia-said-to-plan-yuan-bondsale-as-sanctions-threat-nears. 
próximo suas operações em dólares e passar a usar o euro em suas transações internacionais. ${ }^{29}$ A questão sensível neste caso é que a Venezuela se tornou a mais importante reserva mundial de petróleo, ultrapassando inclusive a Arábia Saudita. Ademais, o governo venezuelano vem propondo a estruturação de um bloco alternativo, fora do dólar, em parceria com os principais rivais dos Estados Unidos: a China e a Rússia ${ }^{30}$. Trata-se, portanto, de uma disputa também monetária, envolvendo a cotação da mercadoria mais estratégica do sistema, cujo domínio tem efeitos importantes sobre a hierarquia monetária internacional, dado o grau de dependência energética (petróleo) da maior parte dos países.

Ainda no que se refere à cotação (precificação) de recursos naturais, a China detém o controle sobre um conjunto significativo de recursos minerais estratégicos. Segundo o British Geological Survey (BGS) de 2015, a China concentra 96\% da produção de terras raras do mundo. Na lista dos recursos com maior risco de oferta atual, a China controla a produção de 23 dos 41 elementos ou grupo de elementos da lista. Sendo que a China é a maior produtora dos treze elementos com maior risco de oferta e possui as maiores reservas já descobertas dos sete elementos com maior risco de oferta. Com efeito, embora esses mercados sejam em geral organizados em dólar, não é difícil perceber que a China possui uma posição estratégica privilegiada para redefinir em algum momento a outra unidade monetária de cotação desses produtos no mercado internacional.

A segunda fonte com potencial de enfrentamento à atual hierarquia monetária são as iniciativas, embora incipientes, de criação de novas instituições financeiras multilaterais com capacidade de disputar com o FMI e o Banco Mundial os empréstimos de estabilização e os financiamentos internacionais. Nos regimentos constitutivos dessas instituições, ficou definido desde 1944 o dólar como moeda de conta quanto ao estoque de capital do Fundo e do Banco (BIRD na época) e aos aportes dos países signatários. Nesse sentido, o Arranjo Contingente de Reservas e o Novo Banco de Desenvolvimento dos BRICS, se consolidados, esvaziam o poder de enquadramento das instituições consagradas nos Acordos de 1944 sobre os países com dificuldades em seus Balanços de Pagamentos. Em caso de sucesso e projeção global, as instituições financeiras dos BRICS ganham potencial para, em outro momento, pressionarem a própria hierarquia monetária internacional atual, por meio da difusão do uso de uma moeda diferente do dólar. No entanto, essa iniciativa ainda dá seus primeiros passos e depende da consolidação do bloco do BRICS e de suas instituições financeiras. Algo que provavelmente levará alguns anos se não sofrer percalços pelo caminho.

Uma terceira fonte de pressão sobre a atual hierarquia monetária é o projeto geopolítico e geoeconômico chinês da Nova Rota da Seda, que articula mais de setenta países, abarcando

(29) News Click. Disponível em: https://www.newsclick.in/venezuela-switches-dollar-euro-foreign-exchange-tackle-usblockade; e https://www.rt.com/news/441448-venezuela-drops-dollar-currency/.

(30) Reuters. Disponível em: https://www.reuters.com/article/us-india-oil-venezuela/venezuela-hopes-to-create-nondollar-trading-bloc-idUSKCN1Q11GF. 
uma área que vai do Pacífico-Sul ao Mar do Norte, alcançando a Costa Leste da África e o Mediterrâneo. À medida que esse projeto envolver países em acordos bilaterais para construção de projetos de infraestrutura, tenderá a ocorrer a projeção do renminbi sobre esse espaço, sobretudo nos países que apresentam vulnerabilidades e dependência com a China. Trata-se, como visto, de um exercício de construção de relações econômicas hierarquizadas, muitas vezes provenientes de negociações entre atores com forte assimetria econômica, política e militar.

Portanto, tem havido nos dias atuais no mundo um questionamento do privilégio exorbitante ampliado de que desfrutam os Estados Unidos, com base em algumas iniciativas para transformação da atual hierarquia monetária internacional. Embora algumas sejam efêmeras e desiguais, elas não são resultado de um jogo de mercado, mas de ações estratégicas de importantes Estados nacionais, cujo cálculo e racionalidade são geopolíticos. Como se trata de um jogo, no limite, de soma zero, não será surpreendente que as tensões aumentem nas regiões estratégicas para a hierarquização do sistema, como, por exemplo, na Venezuela e no Oriente Médio. O avanço dessas iniciativas de desdolarização compele os Estados Unidos a uma reação mais assertiva e, possivelmente, mais violenta de sua diplomacia monetária em defesa de sua moeda no sistema internacional, como as que ocorreram em 1973-74 e em 1979. Algo que não é improvável no cenário atual e num futuro próximo.

\section{Conclusão}

A capacidade de financiamento e gasto dos Estados Unidos no mundo pós-Guerra Fria está ligada à montagem de um sistema internacional ancorado monetariamente no dólar e financeiramente nos U.S. Treasuries. Esse sistema vem permitindo aos Estados Unidos alavancar sua efetiva presença militar em todos os continentes, mares e oceanos. Para os Estados Unidos, o endividamento excessivo assemelha-se mais a um sinal de força e poder, baseado num sistema de extorsão e tributação global. No século XXI, a despeito do fim da Guerra Fria, os Estados Unidos seguem se projetando e aumentando sua presença militar global, intensificando sua rivalidade com outras potências do sistema internacional, sobretudo China e Rússia.

No campo monetário, existem algumas incipientes iniciativas de confrontação efetiva. Destacam-se: (i) propostas de comercialização do petróleo com base em moedas diferentes ao dólar; (ii) a montagem de instituições financeiras multilaterais que rivalizam com o Fundo Monetário Internacional e o Banco Mundial nas finanças internacionais; e (iii) o projeto da Nova Rota da Seda cujos efeitos potenciais são a expansão da própria moeda chinesa. Nesse sentido, na atual conjuntura, os fundamentos do privilégio exorbitante dos Estados Unidos podem estar sendo questionados. 
Geopolítica e diplomacia monetária: o sistema dólar de tributação global e as iniciativas de desdolarização...

\section{Bibliografia}

ARRIGHI, G. O longo século XX. Rio de Janeiro: Contraponto, 1996.

CINTRA, M. A. M.; MARTINS, A. R. A. (Org.). As transformações no sistema monetário internacional. Brasília: Ipea, 2013.

CLARK, W. R. Petrodollar warfare: oil, Iraq and the future of the dollar. Canada: New Society Publisher, Gabriola Island, 2005.

ENGDAHL, W. A century of war. Revised Edition. Pluto Press, 2004.

FUNABASHI, Yoichi. Managing the dollar: from the Plaza to the Louvre. Washington, DC: Institute for International Economics, 1988.

GRZYBOWSKI, Kazimierz. Control of U.S. trade with China: an overview. Law and Contemporany Problems, p. 175-181, Summer, 1973.

HELLEINER, E. States and the reemergence of global finance: from Bretton Woods to the 1990s. Cornell University Press, 1994.

HICKS, J. R. A market theory of money. Oxford: Clarendon Press, 1989.

INNES, A. M. (1913). What is money? Banking Law Journal, p. 377-408, May 1913.

KEYNES, J. M. (1930), A treatise on money, v. 1. CWJMK, v. V. Cambridge: Cambridge University Press, 1979.

KINDLEBERGER, C. International capital moviments. Cambridge University Press, 1987.

KINDLEBERGER, C. A financial history of Western Europe. Oxford University Press, 1993.

KNAPP, G. F. (1905).The state theory of money. San Diego: Simon Publications, 2003.

BRANDÃO, L. A. G. A. Poder e petróleo: estratégia na era Reagan sob o prisma da longa duração. Tese (Doutorado)-PEPI / IE-UFRJ, Rio de Janeiro, 2016.

MARTINS, A. R. A. A China na ordem monetária internacional: evolução da internacionalização do renminbi. In: ENEPI, 2, Rio de Janeiro, UFRJ, maio de 2017. Anais...

MAZAT, N. A Rússia dos anos 90: crônica de um desastre anunciado. Crítica Econômica, fev. 2008.

METRI, M. Hierarquia e competição entre estados nacionais no atual sistema monetário internacional. Dissertação (Mestrado)-PPGE / IE-UFRJ, Rio de Janeiro, 2003.

METRI, M. Petróleo, diplomacia e divisas internacionais. Outras Palavras, dez. 2013.

METRI, M. Poder, riqueza e moeda na Europa Medieval. Rio de Janeiro: Editora FGV, 2014.

METRI, M. A ascensão do dólar e a resistência da libra: uma disputa político- diplomática. Revista Tempo do Mundo, v. 1, p. 65-92, 2015. 
METRI, M. A diplomacia monetária dos Estados Unidos nos anos setenta. Revista Tempo do Mundo, v. 3, n. 1, p. 155-179, 2017.

METRI, M. A Virtù econômico-monetária. Brazil. J. Polit. Econ., v. 38, n. 3, p. 510-525, 2018.

MINSKY, H. Financial integration and national economic policy. In: CICLO DE SEMINÁRIOS, 25 Anos de Economia na Unicamp, Campinas, ago./out. 1993.

SPIRO, E. D. The hidden hand of American hegemony: petrodollar recycling and international markets. London: Cornell University Press, 1999.

TAVARES, M. C. A retomada da hegemonia norte-americana. Revista de Economia Política, São Paulo, v. 5, n. 2, p. 5-15, abr./jun. 1985.

TAVARES, M. C.; MELIN, L. E. Pós-escrito 1997: a reafirmação da hegemonia norteamericana, in: TAVARES, M. C.; FIORI, J. L. (Org.). Poder e dinheiro: uma economia política da globalização, Petrópolis: Ed. Vozes, 1997.

VINE, D. Base nation: how U.S. Military bases abroad harm America and the world. New York: Metropolitan Books, 2015.

YERGIN, D. (1991). O petróleo: uma história mundial de conquistas, poder e dinheiro. São Paulo: Paz e Terra, 2010. 